\title{
Rancang Bangun Pemantau Detak Jantung dan Suhu Tubuh Portabel Dengan Sistem IoT
}

\author{
Indra Agustian \\ Teknik Elektro Universitas Bengkulu \\ Jl. Kandang Limun Bengkulu \\ indraagustian@unib.ac.id
}

\begin{abstract}
AbSTRAK
Pemeriksaaan detak jantung dan suhu tubuh dapat sangat membantu tenaga kesehatan untuk mendiagnosis kondisi kesehatan pasien. Untuk memudahkan tenaga kesehatan, maka dirancang alat pemantau detak jantung portabel dengan sistem IoT. Desain portabel ditujukan agar alat ini mudah dibawa, dan mudah digunakan oleh pasien yang sedang rawat jalan, sedangkan fungsi IoT, tenaga kesehatan dapat memantau kondisi pasien dari jarak jauh dan secara kontinyu. Detak jantung dideteksi menggunakan sensor ECG AD8232, dan suhu tubuh dideteksi menggunakan sensor DS18B20 terkoneksi ke mikrokontroler. Pengujian menunjukkan sensor ECG AD8232 dan sensor suhu DS18B20 sensor sangat layak digunakan. Sistem IoT yang dibangun dapat membantu tenaga kesehatan dan pasien untuk mendapatkan penanganan segera jika terjadi keaadan abnormal.

Kata Kunci: pemantau detak jantung, pemantau suhu tubuh, sistem IoT kesehatan
\end{abstract}

\section{PENDAHULUAN}

Perkembangan teknologi di bidang kesehatan telah mengalami perkembangan pesat baik pada proses pengobatan pasiennya, teknologi untuk pengembangan ilmu kesehatan itu sendiri. Berbagai macam proses pengoperasian rumah sakit sudah banyak yang mengalami perkembangan dengan menggantikan kinerja manusia menjadi sistem-sistem otomatis. Salah satu bentuk penerapan sistem otomatis tersebut adalah pada bagian monitoring detak jantung dan suhu tubuh manusia.

Proses pemantauan detak jantung dan suhu tubuh manusia yang terjadi selama ini masih banyak dilakukan secara manual dan ditempat tertentu. Perawat atau dokter melakukan pemeriksaan jumlah detak jantung dan suhu tubuh manusia secara berkala ketika pasien dirawat. Sedangkan proses pemantauan detak jantung dan suhu tubuh manusia tersebut tidak boleh lengah agar tidak membahayakan pasien sehingga harus dilakukan proses monitoring secara berkala oleh perawat atau dokter [1].

Ketika terjadi kelalaian pemantauan atau bahkan kondisi tidak tahu pasien normal atau tidak maka dapat menimbulkan hal-hal berbahaya pada pasien karena terlambatnya penanganan. Jika tidak segera secepatnya diatasi pasien akan mengalami koma bahkan kematian. Oleh karena itu diperlukan alat pemantau yang dapat memberikan informasi secara kontinyu dan dapat dipantau dari jarak jauh, sehingga penanganan secara cepat dapat dilakukan jika terjadi suatu keadaan abnormal pada detak jantung dan suhu tubuh pasien.

Sebelumnya, Park [2] merancang alat deteksi detak jantung berbasis telepon pintar android, menggunakan komponen perangkat keras seperti chip FPGA sebagai mikrokontroller, modulator delta, dan USB 1.1 PHY/LINK sebagai pengirim data ke telepon pintar. Penelitian Park cukup kompleks dan membutuhkan biaya yang tidak murah. Penmatsa [3] merancang sistem deteksi detak jantung juga berbasis telepon pintar, selain sensor EKG juga ditambahkan sensor suhu, dan sensor oksimeter pulsa dengan sistem komunikasi Bluetooth. Keterbatasan penelitian Lakshmi adalah keterbatasan jangkauan Bluetooth. Jadhav [4] merancang alat pemantauan kesehatan yang juga berbasis telepon pintar, namun parameter yang dipantau cukup kompleks, seperti tekanan darah, SpO2, detak jantung, EKG, suhu tubuh, laju nafas dan tingkat glukosa. Khalaf [5] merancang alat deteksi jantung menggunakan modul wifi Xbee S6B sebagai transmisi dengan menggunakan protokol 802.11.

Berbeda dengan dengan penelitian-penelitian sebelumnya di atas, pada penelitian ini alat pemantau yang dirancang bersifat portabel dan menggunakan teknologi Internet of Think(IoT) yang memungkin pemantauan dapat dilakukan dari jarak jauh. Alat yang dirancang juga bersifat ekonomis atau berbiaya rendah, menggunakan mikrokontoler ber-platform Arduino, sensor detak jantung ECG AD8232 [6], sensor suhu DS18B20 [7] dan ESP8266 [8] dan webserver Internet of Think(IoT) [9]. Alat pemantau detak jantung dan suhu tubuh pada manusia ini menggunakan mikrokontroler yang telah diprogram kemudian menggunakan modul wifi sebagai pengirim data ke IoT cloud server, data pengukuran berupa detak jantung BPM (Beats Per Minute) dan suhu tubuh dapat diakses secara online via telepon pintar atau komputer.

Penelitian ini dapat berkontribusi untuk mempermudah dokter beserta perawat dalam memantau 


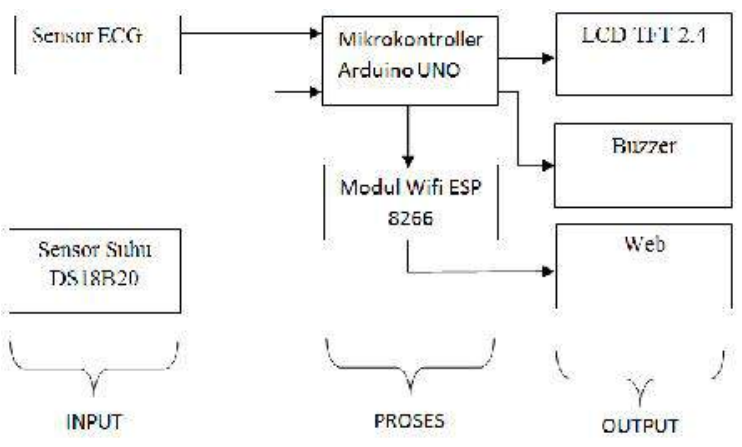

Gambar 1. Skema Perangkat Keras Sistem

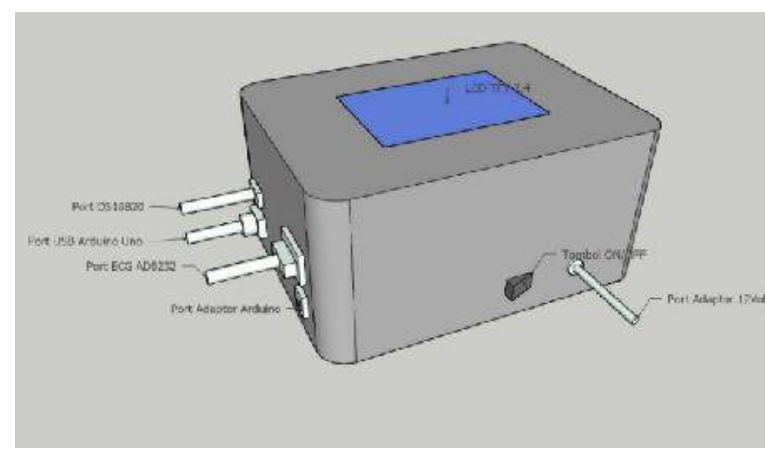

Gambar 2. Desain fisik alat

pasien dirumah sakit dengan hanya melihat di layar komputer atau telepon pintar dan pasien juga dapat melihat kondisi kesehatannya, sehingga dapat dilakukan penanganan lebih awal jika terjadi sesuatu yang abnormal.

\section{DESAIN SISTEM}

Pada penelitian ini dirancang prototipe untuk mengetahui kondisi jantung dan suhu tubuh untuk melihat kondisi yang sehat atau tidak sehat pada manusia itu sendiri. Gambar 1 memperlihatkan kesatuan hubungan dari setiap bagian komponen atau perangkat keras pada penelitian ini, sedangkan desain fisik alat ditunjukkan pada Gambar 2. Sisi masukan terdapat 2 buah sensor utama yaitu sensor ECG AD8232 dan sensor suhu

DS18B20. Sensor suhu akan menjadi masukan untuk pembacaan suhu, sedangkan sensor ECG akan jadi masukan untuk pembacaan denyut jantung.

Data dari sensor masuk ke mikrokontroler yang menjadi pusat kontrol pengolahan data selanjutnya ditampilkan pada LCD TFT dan dikirim ke IoT cloud server ThingSpeak.com melalui ESP8266. Data yang diterima server IoT ditampilkan dalam bentuk grafik dan dapat diunduh.
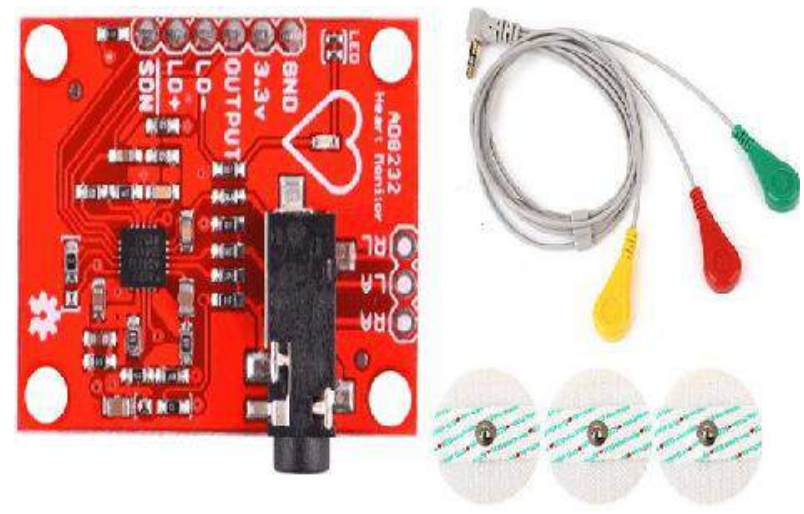

Gambar 3. Modul Sensor ECG AD8232 [10]

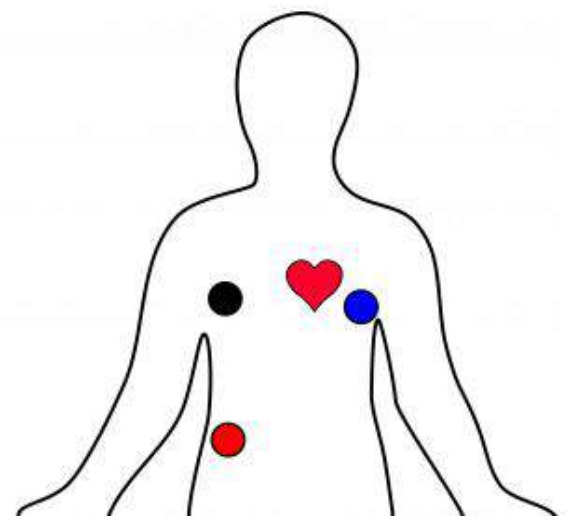

Gambar 4. Lokasi Elektroda, biru LA, hitam RA, merah RL[10]

\section{Sensor ECG AD8232}

Modul Sensor ECG yang digunakan pada penelitian ini adalah tipe "Fully integrated single-lead ECG front end" AD8232 (Gambar 3). Kebutuhan rangkaian filter pendukung AD8232 tergantung pada implementasi penggunaan. Ada tiga konfigurasi rangkaian utama yang dapat digunakan berdasarkan lokasi penempatan elektroda, pertama rangkaian untuk pengukuran detak jantung dengan lokasi deteksi dekat dengan area jantung, rangkaian ini hanya menggunakan dua elektroda. Kedua, rangkaian dengan lokasi elektroda pada lengan yang biasa digunakan untuk mendeteksi denyut nadi, menggunakan tiga elektroda. Ketiga, rangkaian untuk "cardiac monitoring", lokasi elektroda seperti pada Gambar 4, konfigurasi ini dirancang untuk memantau bentuk gelombang EKG. Meskipun pada penelitian ini hanya mengamati detak jantung dalam BPM, namun dengan target untuk dapat dikembangkan lebih lanjut, penelitian ini menggunakan konfigurasi ketiga yang ditunjukkan pada Gambar 5. Persamaan untuk mencari nilai ECG dengan satuan tegangan sebenarnya, dapat dilihat pada pada persamaan (1). 


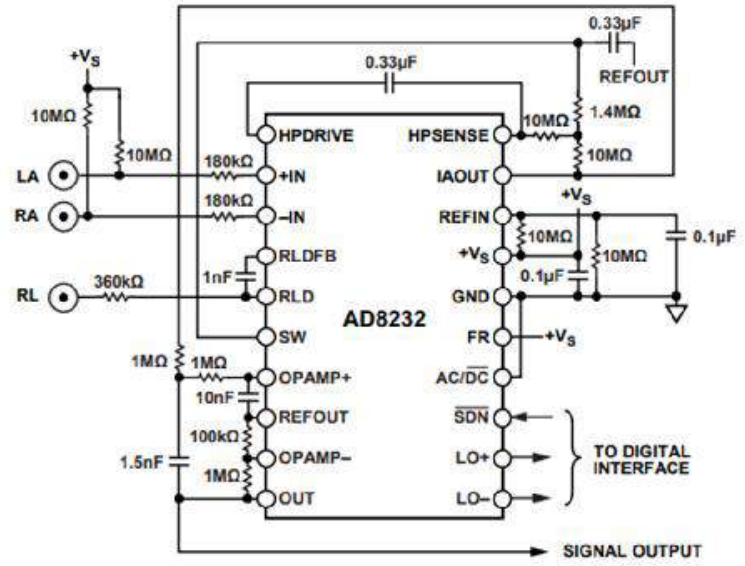

Gambar 6. Konfigurasi Untuk “Cardiac Monitoring”[6]

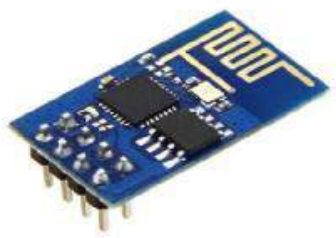

Gambar 7. Modul ESP8266[8]

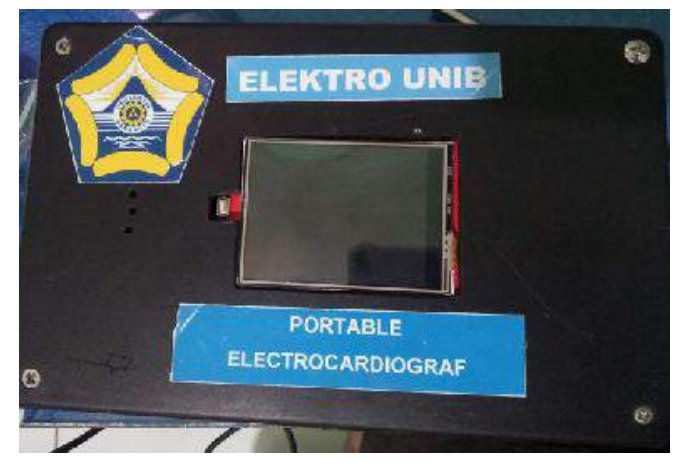

(a)

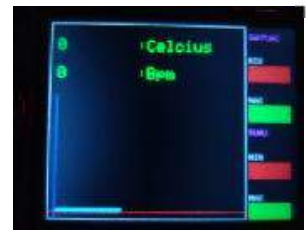

(b)

(c)

Gambar 8. (a) Prototipe deteksi detak jantung dan suhu tubuh, tampilan indikator pada LCD (b) Kondisi sensor tidak membaca (c) Kondisi sensor sembaca kondisi normal.

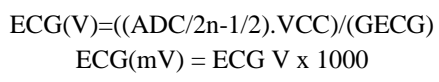

ECG(V) : ECG dalam satuan Volt(V)

$\mathrm{ECG}(\mathrm{mV})$ : ECG dalam satuan milivolt $(\mathrm{mV})$

VCC : Tegangan Operasi(3.3v)

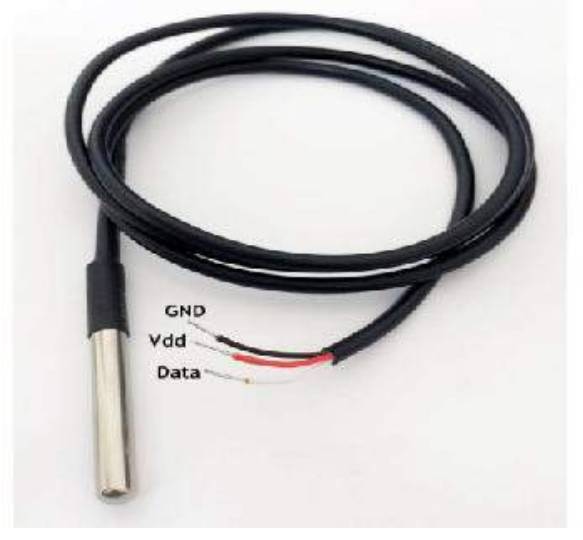

Gambar 5. Sensor Suhu DS18B20 [7]

GECG : Penguatan Sensor(1100)

Tabel 1. Detak Jantung Normal pada saat istirahat[11]

\begin{tabular}{lc}
\hline \multicolumn{1}{c}{ Umur } & $\begin{array}{c}\text { Rata-rata detak jantung } \\
\text { normal pada saat istrahat } \\
\text { (BPM) }\end{array}$ \\
\hline$<1$ tahun & $100-160$ \\
Anak 1-10 tahun & $70-120$ \\
Anak Remaja 11-17 tahun & $60-100$ \\
$>$ 17 tahun keatas & $60-100$ \\
\hline
\end{tabular}

Tabel 2. Suhu Tubuh Normal Berdasarkan Umur

\begin{tabular}{cc}
\hline Umur & $\begin{array}{c}\text { Rata-rata suhu tubuh } \\
\text { normal }\left({ }^{\circ} \mathrm{C}\right)\end{array}$ \\
\hline Bayi dibawah 1 tahun & $36,1-37,7$ \\
Anak 1-10 tahun & $36,3-37,7$ \\
Remaja dan Dewasa & $36,5-37,5$ \\
\hline
\end{tabular}

ADC : nilai sampel dari chanel

$\mathrm{n} \quad$ : jumlah bit saluran

\section{Sensor DS18B20}

DS18B20 adalah sensor suhu digital seri terbaru dari Maxim IC. Sensor ini mampu membaca suhu dengan ketelitian 9 hingga 12 -bit, rentang $-55^{\circ} \mathrm{C}$ hingga $125^{\circ} \mathrm{C}$ dengan ketelitian $\left(+/-0.5^{\circ} \mathrm{C}\right)$. Setiap sensor yang diproduksi memiliki kode unik sebesar 64-Bit yang disematkan pada masing-masing chip, sehingga memungkinkan penggunaan sensor dalam jumlah besar hanya melalui satu kabel saja (single wire data bus/1-wire protocol). Gambar 4 menunjukkan Sensor DS18B20 yang digunakan.

\section{ESP8266 Transceiver WiFi}

Modul wireless ESP8266[10] merupakan modul low-costWi-Fi dengan dukungan penuh untuk penggunaan TCP/IP. Modul ini di produksi oleh Espressif 


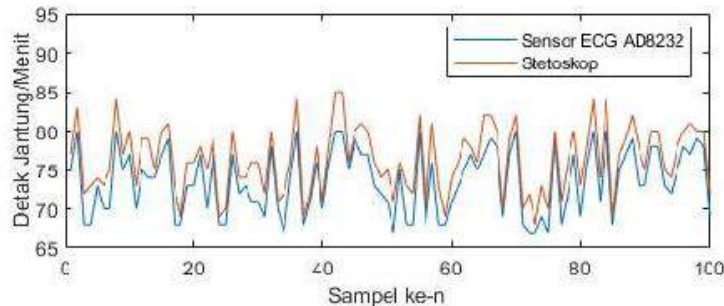

(a)

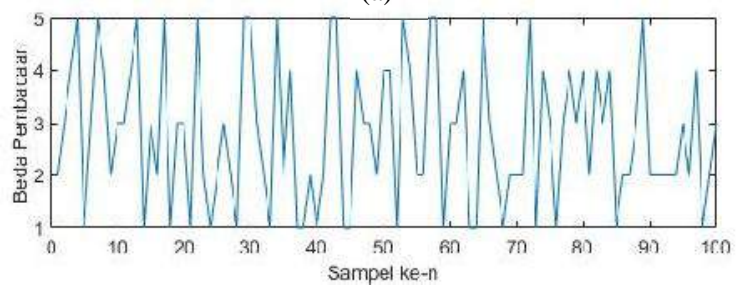

(b)

Gambar 9. Grafik pengukuran detak jantung (a) ECG AD8232 vs stetoskop (b) selisih pengukuran

Chinese Manufacturer. Pada tahun 2014, AI-Thinker manufaktur pihak ketiga dari modul ini mengeluarkan

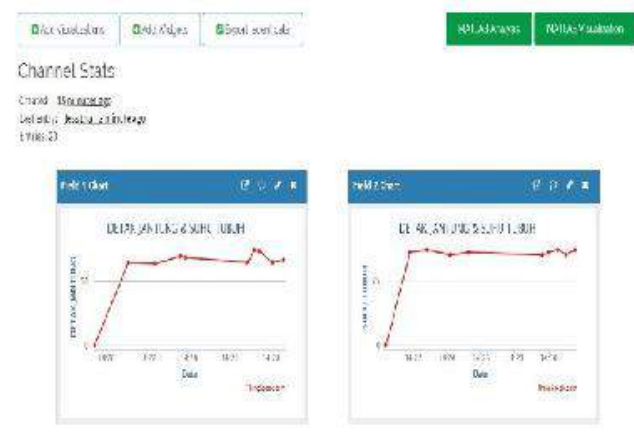

Gambar 11. Tampilan IoT client side ThingSpeak.com

modul ESP-01, modul ini menggunakan AT-Command untuk konfigurasinya. Harga yang murah, penggunaan daya yang rendah dan dimensi modul yang kecil menarik banyak developer untuk ikut mengembangkan modul ini lebih jauh. Pada Oktober 2014, Espressif mengeluarkan software development kit (SDK) yang memungkinkan lebih banyak developer untuk mengembangkan modul ini. Bentuk fisik ESP8266 yang digunakan dapat dilihat pada Gambar 7.

Alat dirancang untuk digunakan pada pasien yang sedang dalam perawatan terutama rawat jalan, sehingga sistem peringatan dirancang dengan skenario untuk pengguna dalam keadaan istirahat dan disesuaikan dengan umur pengguna berdasarkan Tabel 1 dan 2.

\section{HASIL DAN PEMBAHASAN}

Pengujian pertama dilakukan secara offline, data hasil tampil di LCD dengan indikator menunjukkan jika tubuh manusia normal atau abnormal. Jika nilai tidak sesuai maka indikator buzzer akan berbunyi. Dapat dilihat

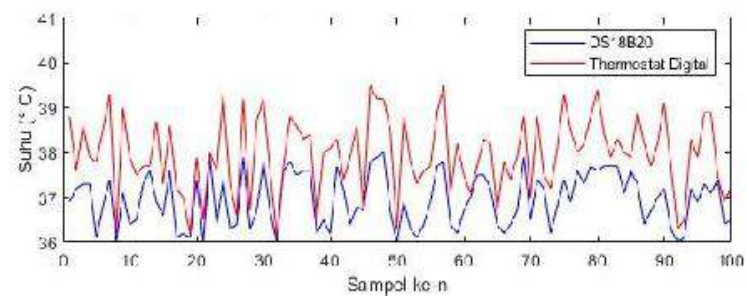

(a)

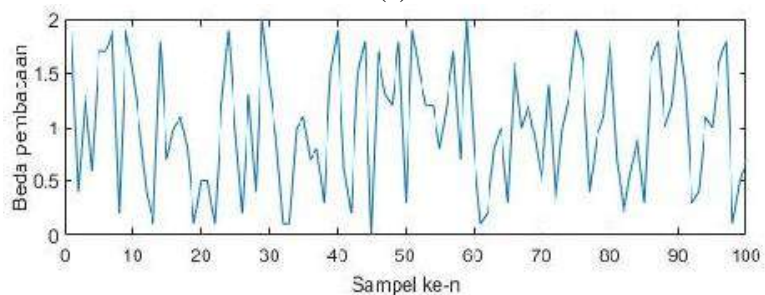

(b)

Gambar 10. Grafik pengukuran Suhu (a) DS18B20 vs Thermostat digital (b) selisih pengukuran

pada Gambar 8, prototipe hasil rancangan dan contoh tampilan indikator detak jantung dan suhu tubuh manusia, bar merah untuk tidak normal, bar hijau untuk keadaan normal.

Pengujian pengukuran detak jantung dan suhu tubuh dilakukan pada 100 sampel pada umur 11-17 tahun. Indikator Normal dan tidak normal berdasarkan Tabel 1 dan Tabel 2. Pengukuran detak jantug dibandingkan dengan pegukuran stetoskop biasa, dan pengukuran suhu dibandingkan dengan thermostat digital biasa. Hasil pengukuran ditampilkan pada Gambar 9 dan 10. Dari gambar tersebut bahwa perbedaan hasil pengukuran detak jantung maksimal adalah 5 detak/permenit dan perbedaan pengukuran suhu maksimal $2{ }^{\circ} \mathrm{C}$. Standar deviasi perbedaan pengukuran detak jantung adalah 1.3676 dan standar deviasi perbedaan pengukuran suhu 0.5916, hal ini menunjukkan bahwa alat ukur yang dipakai masih cukup efektif untuk digunakan.

Dari pengujian, semua detak jantung teramati dalam keadaan normal, sedangkan teramati ada 23 sampel yang terdeteksi memiliki suhu tubuh di atas $37.5{ }^{\circ} \mathrm{C}$ dan maksimal terdeteksi 1 sampel pada suhu $38^{\circ} \mathrm{C}$, karena gabungan pengukuran masih dalam ambang batas wajar sistem belum memberikan peringatan. Untuk sampel yang diujicobakan sistem di desain memberi peringatan jika suhu tubuh diatas $38{ }^{\circ} \mathrm{C}$ dan dengan aktivitas detak jantung abnormal.

Pada pengujian online data pengukuran detak jantung dikirim ke cloud server IoT ThingSpeak.com melalui ESP01 sehingga data dapat dipantau secara online dan dapat juga diunduh untuk dianalisis lebih lanjut.

Gambar 11 menunjukkan grafik data detak jantung dan suhu tubuh yang dikirimkan dari alat. Data detak jantung dikirimkan per menit, sedangkan data suhu 
dikirimkan setiap 20 detik. ThingSpeak memiliki batasan periode upload per 15 detik.

\section{KESIMPULAN}

Prototipe pemantau detak jantung dan suhu tubuh portabel dengan menggunakan sistem IoT pada penelitian ini cukup efektif dan dapat memberikan kontribusi yang signifikan untuk membantu tenaga kesehatan untuk memantau kesehatan pasien dari jarak jauh. Sistem peringatan keadaan abnormal juga sangat membantu pasien untuk segera meminta bantuan penanganan segera. Untuk penelitian lanjutan dapat dikembangkan sistem IoT yang dapat memberikan peringatan jarak jauh.

\section{DAFTAR PUSTAKA}

[1] A. Agustiawan, A. Surtono and G. A. Pauzi, "Sistem Instrumentasi Akuisisi Data EKG 12 Lead Berbasis Komputer," Jurnal Teori dan Aplikasi Fisika, vol. 4, 2016.

[2] J. Park, K. Seong, H.-K. Noh, W.-C. Lee, B. Kim, J.-Y. Sim and H.-J. Park, "An ECG monitoring system using android smart phone," in 2016 IEEE International Conference on Consumer Electronics-Asia (ICCE-Asia), 2016.

[3] P. L. Penmatsa and D. V. R. K. Reddy, "Smart detection and transmission of abnormalities in ecg via bluetooth," in 2016 IEEE International Conference on Smart Cloud (SmartCloud), 2016.

[4] K. B. Jadhav and U. M. Chaskar, "Design and development of smart phone based ECG monitoring system," in 2017 2nd IEEE International Conference on Recent Trends in

[11] Kleiger, Robert E., et al. "Time domain measurements of heart rate variability." Cardiology clinics 10.3 (1992): 487-498.
Electronics, Information \& Communication Technology (RTEICT), 2017.

[5] A. Khalaf and R. Abdoola, "Wireless body sensor network and ECG Android application for eHealth," in 2017 Fourth International Conference on Advances in Biomedical Engineering (ICABME), 2017.

[6]] Analog.com, "AD8232, Single-Lead, Heart Rate Monitor Front End," Analog Devices, 2019. [Online]. Available: https://www.analog.com/en/products/ad8232. html. [Accessed 118 2019].

[7] Integrated, Maxim, " DS18B20 Datasheet" Maxim Integrated, 2019. [Online]. Available: https://datasheets.maximintegrated.com/en/ds/ DS18B20.pdf. [Accessed 88 2019].

[8] Espressif Systems, "ESP8266EX," Espressif Systems (Shanghai) CO., LTD, 2019. [Online]. Available:

https://www.espressif.com/en/products/hardw are/esp8266ex/overview. [Accessed $12 \quad 8$ 2019].

[9] J. Gubbi, R. Buyya, S. Marusic and M. Palaniswami, "Internet of Things (IoT): A vision, architectural elements, and future directions," Future generation computer systems, vol. 29, pp. 1645-1660, 2013.

[10] M. Alam, https://how2electronics.com/, how2electronics, 2019. [Online]. Available: https://how2electronics.com/ecg-monitoringwith-ad8232-ecg-sensor-arduino/. [Accessed 148 2019]. 